DOI: 10.12731/2218-7405-2018-2-84-93

УДК 159.9.072

\title{
ПСИХОЛОГИЧЕСКОЕ СОПРОВОЖДЕНИЕ ДЕЗАДАПТИРОВАННЫХ ИНОСТРАННЫХ СТУДЕНТОВ С ПРОЯВЛЕНИЯМИ АДДИКЦИИ
}

\section{Мурашкин М.M.}

Цель. Статья посвящена актуальной теме в рамках современной парадигмы учебной миграчии. Предметом анализа является психологическое сопровождение иностранных студентов, как фактор влияния на их дезадаптированность. В качестве иеели выступает коррекиия дезадаптивного поведения иностранных студентов с проявлениями аддикиии.

Методология и методы работы. Фундаментом исследования является интегративный подход в психотерапевтической работе, теории сочиильной психологии малой группь, мультикультуральное направление в области арт-терапии и др. Основу психологического сопровождения составляет сочиально-психологический тренинг; поведенческая терапия; арт-терапия; ролевые игры; межкультурные мероприятия.

Результаты исследования. Статья содержит результаты теоретического анализа подходов к изучению адаптаџионного процесса иностранных студентов к новым условиям соииокультурной среды. Представлены результаты апробации программы социально-психологического сопровождения дезадаптированных иностранных студентов с проявлениями аддикции. $B$ апробации программы приняло участие 42 иностранных студента в составе экспериментальной группы.

Область применения результатов. Основные выводы и результаты исследования могут быть использованы администрацией вузов в качестве воспитательной работы с иностранными студентами. 
Ключевые слова: соииально-психологическое сопровождение; дезадаптированный иностранный студент; адаптащия; аддикиия; соииально-психологический тренинг.

\section{PSYCHOLOGICAL SUPPORT OF DENADAPTED FOREIGN STUDENTS WITH MANIFESTATIONS OF ADDICTION}

\section{Murashkin M.M.}

Purpose. The article is devoted to the actual topic within the framework of the modern paradigm of educational migration. The subject of the analysis is the psychological accompaniment of foreign students, as a factor of influence on their disadaptation. The goal is to correct the disadaptive behavior of foreign students with manifestations of addiction.

Methodology and methods of work. The foundation of the research is an integrative approach in psychotherapeutic work, the theory of social psychology of a small group, a multicultural trend in the field of art therapy, etc. The basis of psychological support is socio-psychological training; behavioral therapy; art therapy; role-playing games; intercultural activities.

Results of the research. The article contains the results of a theoretical analysis of approaches to studying the adaptation process of foreign students to the new conditions of a sociocultural environment. The results of approbation of the program of social and psychological support for de-adapted foreign students with manifestations of addiction are presented. Approximately 42 foreign students participated in the testing of the program as part of the experimental group.

Scope of the results. The main conclusions and results of the study can be used by the administration of higher education institutions as an educational work with foreign students.

Keywords: socio-psychological support; de-adapted foreign student; adaptation; addiction; socio-psychological training. 
Проблема миграции в последние годы стала особо актуальной. Особый вопрос стоит в миграционных потоках, целью которых является получение высшего образования. Данный аспект получил осмысление в исследованиях многих российских ученых (С.К. Бондырева, В.В. Гриценко, В.В. Константинов, Т.Г. Дичев, Г.У. Солдатова, Т.Г. Стефаненко, Н.Д. Султанова, О.Е. Хухлаев, О.А. Шарова, А.И. Щепина и др.). Ситуация, когда молодой человек-мигрант поступает в учебное заведение и становится студентом, рассматривается исследователями как сложная стрессогенная ситуация, сопровождающаяся переживанием конфликта между привычными для молодежи нормами и ценностями, характерными для той среды, которую он покинул, и нормами и ценностями, характерными для новой социальной среды.

Адаптация определяется как постоянный процесс активного приспособления индивида к условиям социальной среды и как результат этого процесса. Результатом адаптации является адаптированность мигранта к новым социокультурным особенностям, принятие новых условий, установление взаимоотношений, необходимых для жизнедеятельности и оптимизации самочувствия.

В работах, посвященных изучению особенностей адаптации студентов-мигрантов, отмечается, что процесс их адаптации характеризуется на начальном этапе «стрессом аккультурации». Результатом данного процесса является дезадаптация, депрессивные состояния, повышение агрессии и различные негативные психоэмоциональные проявления, аддиктивное поведение.

В современной психологической науке проведен ряд исследований, посвященных проблеме адаптации мигрантов:

- социально-психологическое сопровождение процесса адаптации детей-мигрантов в условиях образовательного учреждения Н.И.Ковалевой [1];

- структурно-функциональные характеристики вузовской адаптации студентов Юркиной М.С. [7];

- научно-практические основы психолого-педагогического сопровождения социально-психологической адаптации подростков-мигрантов Сапожниковой И.С. [6]; 
Представленные научные труды и другие исследования в большинстве случаев посвящены изучению адаптации мигрантов школьного возраста, либо особенностям адаптации трудовых мигрантов и студентов-мигрантов. Существуют исследования, которые описывают реализацию программ сопровождения иностранных студентов вуза $[3,4]$. Но, проведенный анализ научноисследовательской литературы показал, что работ, посвященных изучению социально-психологического сопровождения дезадаптированных студентов с различными проявлениями аддикции, на данный момент нет.

Проблема дезадаптации иностранных студентов в новых социокультурных и межличностных пространствах в российских ВУЗах, приобретает большое значение по причине того, что происходит увеличение количества иностранных студентов, обучающихся в России. В этой связи, от того, насколько эффективно иностранные студенты интегрируются в образовательное пространство российского ВУЗа будет складываться и морально-психологическая обстановка в студенческой среде и преодоление коммуникативных барьеров с представителями новой культуры, а также адаптация к быту, климату и языку. Такие исследования могут быть рассмотрены в контексте предотвращения угроз национальной безопасности (распространение экстремистской идеологии, популяризация наркогенной субкультуры), что особенно актуально в современной России [2].

Общее число испытуемых нашего исследования составило 470 иностранных и русскоговорящих студентов 1-2 курсов (из Туркменистана, Узбекистана, Киргизстана, Таджикистана), обучающихся в Пензенском государственном университете. Исследование включает в себя несколько этапов: первый этап - теоретический. Проведен анализ научно-исследовательской литературы по рассматриваемой проблеме; осуществлены постановка и обоснование проблемы, выдвинута цель, сформулированы задачи и гипотезы, отобраны методики для дальнейшего эмпирического исследования, разработана программа социально-психологического сопровождения дезадаптированных студентов с проявлениями аддикции. 
Второй этап исследования - первичная диагностика, с целью выявления уровня адаптивности и аддиктивного поведения. Диагностика студентов в вузе определялась по следующим методикам: методика диагностики социально-психологической адаптации (К. Роджерс, Р. Даймонд в адаптации А.К. Осницкого), многоуровневый личностный опросник «Адаптивность» (МЛО-АМ А.Г. Маклаков, С.В. Чермянин), тест «Склонность к зависимому поведению» В.Д. Менделевича, опросник адаптации личности к новой культурной среде (тест Л.В. Янковского, адаптированный В.В. Контантиновым), а также методы экспертных оценок и анализ личных дел иностранных студентов. На основании замеров адаптированности (низкий или высокий уровень), мы выделили 2 группы: контрольную (группа адаптированных иностранных студентов 1 курса без аддикции - 50 человек в возрасте от 19 до 22 лет) и экспериментальную (дезадаптанты с наличием аддикции - 42 иностранных студента 1 курса в возрасте от 18 до 22 лет).

Анализируя результаты, можно отметить, что для экспериментальной группы характерно: социально-психологическая дезадаптация, повышенный уровень аддиктивности, свойственна интернальность, замкнутость, отчужденность и депрессивность, низкий уровень самовосприятия и эмоционального комфорта, низкий уровень контроля и коммуникативных способностей. Иностранные студенты испытывают потребность в защите и ухода от действительности с помощью употребления алкоголя, что в дальнейшем провоцирует стремление к увеличению остроты ощущений. На следующем этапе мы работали с экспериментальной группой в рамках психокоррекционной работы.

Третий этап исследования - формирующий; этап опытно-экспериментальной работы, заключающийся в апробации разработанной программы социально-психологического сопровождения адаптации «Мы вместе».

Цель программы - коррекция дезадаптивного поведения иностранных студентов с проявлениями аддикции.

Поставленная цель достигается следующими задачами: 
1) познакомить иностранных студентов с многообразием социально-психологических культурно-воспитательных программ Пензенского государственного университета;

2) повысить у иностранных студентов уровень самопринятия, а также изменить установки и ценностную сферу с целью снижения уровня аддиктивности;

3) сформировать умения и навыки ассертивного и адаптивного поведения.

Также, в рамках программы происходит межкультурное взаимодействие и межкультурная коммуникация в процессе обучения иностранных студентов в российском вузе.

Фундаментом программы социально-психологического сопровождения дезадаптивного поведения иностранных студентов служат: социальная психология малой группы (Л.И. Уманский, А.С. Чернышов, В.В. Сарычев, К. Рудестам); интегративный подход в психотерапевтической работе (Г. Пауль, М. Эриксон,), мультикультуральное направление в области арт-терапии (Л. Турнер-Шиклер, Н. Хеуш, Ф. Элдридж, Д. Юрт) и др.

Основная стратегия программы состоит в создании условий, обеспечивающих оптимизацию процесса адаптации иностранных студентов с проявлениями аддикции.

В программе психологического сопровождения адаптации «Мы вместе» приняли участие иностранные студенты, обучающиеся на 1-м первом курсе вуза в составе экспериментальной группы (42 человека) и контрольной группы (50 человек). Формирующий эксперимент проходил в экспериментальной группе. Программа реализовывалась в группе, так как групповая работа является наиболее эффективной для развития ценностно-смысловой сферы; адаптивного и ассертивного поведения. Групповая работа проводилась каждую неделю на протяжении нескольких месяцев.

В описанных выше исследованиях, в программах по адаптации мигрантов, основной акцент делается либо на учебно-образовательный процесс вуза (организация учебного процесса, языковой барьер, взаимоотношения с педагогическим коллективом), либо на условия проживания и приспособления (проживание, питание), либо 
на психологические особенности самих студентов (социокоммуникативный и социокультурный барьеры) $[1,3,4,5,6]$.

Разработанная нами программа «Мы вместе» интегрирует все основные компоненты, необходимые для оптимизации адаптации иностранных студентов в процессе ежедневного взаимодействия с субъектами различных сфер жизнедеятельности новой среды и включает в себя:

- социально-психологические тренинг;

- поведенческая терапия;

- арт-терапия;

- ролевые игры;

- межкультурные мероприятия: «Диалог культур», «Мисс мира» и т.д.

Для сравнения различий в уровне развития дезадаптивного поведения иностранных студентов с проявлениями аддикции, до и после проведения программы, испытуемым экспериментальной и контрольной групп были повторно предъявлены тестовые методики. Для статистической обработки результатов был использован Т-критерий Вилкоксона.

Средние показатели (в баллах) значимо повысились в экспериментальной группе по следующим шкалам: уровень адаптивности повысился на 3,04 балла, уровень принятия себя и других повысился на 1,75 баллов, нервно-психическая устойчивость изменилась на 1,06 баллов, эмоциональный комфорт - на 2,3 балла, коммуникативные способности и интерактивность - на 2,75. При этом снизился уровень отчужденности на 1,14 баллов, депрессивности на 1,05 баллов и уровень аддикции на 1,12 баллов. Сравнив средние баллы показателей по шкалам: ностальгия и моральная нормативность, у испытуемых экспериментальной группы, мы можем сказать, что различия незначительны (0,08 и 0,9 соответственно).

Изменения в контрольной группе студентов не значительны и не подтверждаются статистически.

Достоверность различий в особенностях социально-психологической адаптации и склонности к аддиктивному поведению до и после коррекционного воздействия подтверждена с помощью критерия Вилкоксона (Т эмn. $<$ Т кр. при $\mathrm{p}<0,05$ ). 
Таким образом, комплексная программа социально-психологического сопровождения «Мы вместе» оказывает позитивное воздействие на коррекцию дезадаптации иностранных студентов с проявлениями аддикции. Комплекс созданных мероприятий позволил включиться иностранным студентам в российское принимающее сообщество посредством развития у них социально-личностных качеств через социально-культурную деятельность вуза. У иностранных студентов снизился уровень аддиктивного поведения, уровень депрессивности и отчужденности. При этом повысился уровень социально-психологической адаптации, нервно-психической устойчивости, уровень принятия себя и других, изменился эмоциональный комфорт и улучшились коммуникативные способности, способствующие межличностной коммуникации в различных социальных группах.

Таким, образом, разработанная и апробированная нами программа является эффективным средством психологического сопровождения адаптационного процесса у иностранных студентов с проявлениями аддикции, повышает их адаптивность, коммуникативные способности, интерактивность, снижает уровень отчужденности, депрессивности и аддикции.

\section{Список литературы}

1. Ковалева Н.И. Социально-психологическое сопровождение процесса адаптации детей-мигрантов в условиях образовательного учреждения: автореф. дис. ... канд. психол. наук : 19.00.05. М., 2010. 24 с. Режим доступа: http://nauka-pedagogika.com/psihologiya-19-00-05/ dissertaciya-sotsialno-psihologicheskoe-soprovozhdenie-protsessaadaptatsii-detey-migrantov-v-usloviyah-obrazovatelnogo-uchrezhdeniya

2. Konstantinov V. The Role of the Host Local Population in the Process of Migrants'Adaptation // Soc. Sci. 2017, 6, 92. doi: 10.3390/socsci6030092

3. Konstantinov V. The Homeland Separation as an Example of a Social and Psychological Migration-Related Problem // Indian Journal of Science and Technology. 2017, Vol. 10, Issue 27. doi: 10.17485/ijst/2017/ v10i27/108774 
4. Романова С.А. Теоретические основы программы психологического сопровождения иностранных студентов вуза // Вестник совета молодых ученых и специалистов Челябинской области, № 5. Челябинск, 2014. С. 114-117.

5. Поздняков И.А. Проблемы адаптации иностранных студентов в России в контексте педагогического сопровождения // Известия Российского государственного педагогического университета им. А.И. Герцена, № 121. СПб.: РГПУ им. А.И. Герцена, 2010. С. 161-167.

6. Сапожникова И.С. Научно-практические основы психолого-педагогического сопровождения социально-психологической адаптации подростков-мигрантов: автореф. дис. ... канд. психол. наук : 19.00.07. Ростов-на-Дону, 2007. 24 с. Режим доступа: http://nauka-pedagogika. com/psihologiya-19-00-07/dissertaciyapsihologicheskaya-adaptatsiyapodrostkov-migrantov-kak-komponent-bezopasnosti-munitsipalnogoobrazovatelnogo-prostranstva

7. Юркина М.С. Структурно-функциональные характеристики вузовской адаптации студентов: автореф. дис. ... канд. психол. наук : 19.00.05. Ярославль, 2015. 25 с. Режим доступа: http://nauka-pedagogika. com/psihologiya-19-00-05/dissertaciya-strukturno-funktsionalnyeharaketristiki-vuzovskoy-adaptatsii-studentov

\section{References}

1. Kovaleva N.I. Sotsial'no-psikhologicheskoe soprovozhdenie protsessa adaptatsii detey-migrantov $v$ usloviyakh obrazovatel 'nogo uchrezhdeniya [Socio-psychological support of the process of adaptation of migrant children in the conditions of an educational institution]. M., 2010. 24 p. http://nauka-pedagogika.com/psihologiya-19-00-05/dissertaciya-sotsialno-psihologicheskoe-soprovozhdenie-protsessa-adaptatsii-detey-migrantov-v-usloviyah-obrazovatelnogo-uchrezhdeniya

2. Konstantinov V. The Role of the Host Local Population in the Process of Migrants'Adaptation. Soc. Sci. 2017, 6, 92. doi: 10.3390/socsci6030092

3. Konstantinov V. The Homeland Separation as an Example of a Social and Psychological Migration-Related Problem. Indian Journal of Science and Technology. 2017, Vol. 10, Issue 27. doi: 10.17485/ijst/2017/ v10i27/108774 
4. Romanova S.A. Vestnik soveta molodykh uchenykh i spetsialistov Chelyabinskoy oblasti, № 5. Chelyabinsk, 2014, pp. 114-117.

5. Pozdnyakov I.A. Izvestiya Rossiyskogo gosudarstvennogo pedagogicheskogo universiteta im. A.I. Gertsena, № 121. SPb., 2010, pp. 161-167.

6. Sapozhnikova I.S. Nauchno-prakticheskie osnovy psikhologo-pedagogicheskogo soprovozhdeniya sotsial 'no-psikhologicheskoy adaptatsii podrostkov-migrantov [Scientific and practical basis of psychological and pedagogical support of socio-psychological adaptation of adolescent migrants]. Rostov-on-Don, 2007. 24 p. http://nauka-pedagogika.com/ psihologiya-19-00-07/dissertaciyapsihologicheskaya-adaptatsiya-podrostkov-migrantov-kak-komponent-bezopasnosti-munitsipalnogo-obrazovatelnogo-prostranstva

7. Yurkina M.S. Strukturno-funktsional'nye kharakteristiki vuzovskoy adaptatsii studentov [Structural and functional characteristics of university adaptation of students]. Yaroslavl', 2015. 25 p. http://nauka-pedagogika. com/psihologiya-19-00-05/dissertaciya-strukturno-funktsionalnye-haraketristiki-vuzovskoy-adaptatsii-studentov

\section{ДАННЫЕ ОБ АВТОРЕ}

Мурашкин Михаил Михайлович, аспирант кафедры «Общая психология»

ФГБОУ ВО «Пензенский государственный университет» ул. Красная, 40, г. Пенза, Пензенская обл., 440026, Российская Федерация mura58penza@mail.ru

\section{DATA ABOUT THE AUTHOR}

Murashkin Mikhail Mikhailovich, Post-Graduate Student of the Department "General Psychology"

Penza State University

40, Krasnaya Str., Penza, Penza Region, 440026, Russian Federation

mura58penza@mail.ru 